\title{
CASESERIES
}

\section{Peri-implant Disease-A Clinical Overview (Part 1): Diagnosis, Etiopathology and Risk-Related Aspects}

\author{
Rohit Karnik, Suchetan Pradhan
}

\begin{abstract}
Peri-implant diseases are infectious diseases and a common cause of complications that may be associated with dental implant failures. With increase in numbers of implants, both newly placed and serving under function, it is necessary to achieve an understanding of the current evidence on diagnostic, prognostic and therapeutic aspects of peri-implant diseases. As therapeutic modalities are still evolving and consensus regarding their predictability yet to be achieved, a thorough risk assessment and early diagnosis assume added importance. This two parts review attempts to present the current state of evidence regarding the stated aspects of peri-implant diseases including peri-implant mucositis, peri-implantitis and their treatment modalities. The first part of the series presented in this paper addresses key issues regarding the case- definition, diagnostic, etiopatholgy and risk-related aspects while the second part will address the different treatment modalities with special emphasis on the use of laser radiation for peri-implant diseases.
\end{abstract}

Keywords: Peri-implant disease, Peri-implantitis, Peri-implant mucositis, Risk factors, Diagnosis.

How to cite this article: Karnik R, Pradhan S. Peri-implant Disease-A Clinical Overview (Part 1): Diagnosis, Etiopathology and Risk-Related Aspects. Int J Laser Dent 2012;2(1):18-25.

Source of support: Nil

Conflict of interest: None declared

\section{INTRODUCTION}

Osseointegration is a phenomenon of direct bone to implant contact, defined as; 'direct structural and functional connection between ordered living bone and the surface of a load carrying implant'. ${ }^{1}$ It has been an important scientific breakthrough, leading to significant changes in dental treatment options being provided. ${ }^{2}$ Long-term success of dental implants is dependent upon the maintenance of healthy supporting tissues. ${ }^{3}$ Although, the survival rate of osseointegrated dental implants is high and well documented, ${ }^{4}$ it is evident that successfully integrated implants are susceptible to failure and loss. ${ }^{3-5}$ Based on the nature of cause, implant failure has been categorized as mechanical, biological or iatrogenic. ${ }^{3}$ Mechanical failures include fractures of implant fixture or prosthetic components and iatrogenic failures include nonfunctional implants due to malpositioning . Biological failure is the 'inadequacy of the host tissue to establish or maintain osseointegration, ${ }^{3}$ and is characterized by clinical implant mobility. ${ }^{3,6-8}$ Such failures have also been classified based on the time point of failure as early or late; early being those which occur before osseointegration or loading and late being failures occurring after functional loading. ${ }^{3}$

Bacterial plaque associated inflammation of peri-implant supporting structures and consequent progressive periimplant bone loss are the chief reasons for biologically induced implant failures, accounting for up to half of all late implant failures. ${ }^{3}$ Host response to biofilm formation on implant surfaces includes a series of inflammatory reactions. Peri-implant disease occurs after the successful initial integration of an implant, due to an imbalance between bacterial load and host defence. Initially, the inflammatory reaction is localized to the peri-implant mucosa; this is termed as peri-implant mucositis, but this can subsequently progress and result in the loss of implant supporting alveolar bone; such development is termed as peri-implantitis $^{3,5-8}$ (Figs 1A and B).

More implants are being placed now than ever before ${ }^{2}$ and as their cumulative duration in function increases, an increasing prevalence of peri-implantitis can be
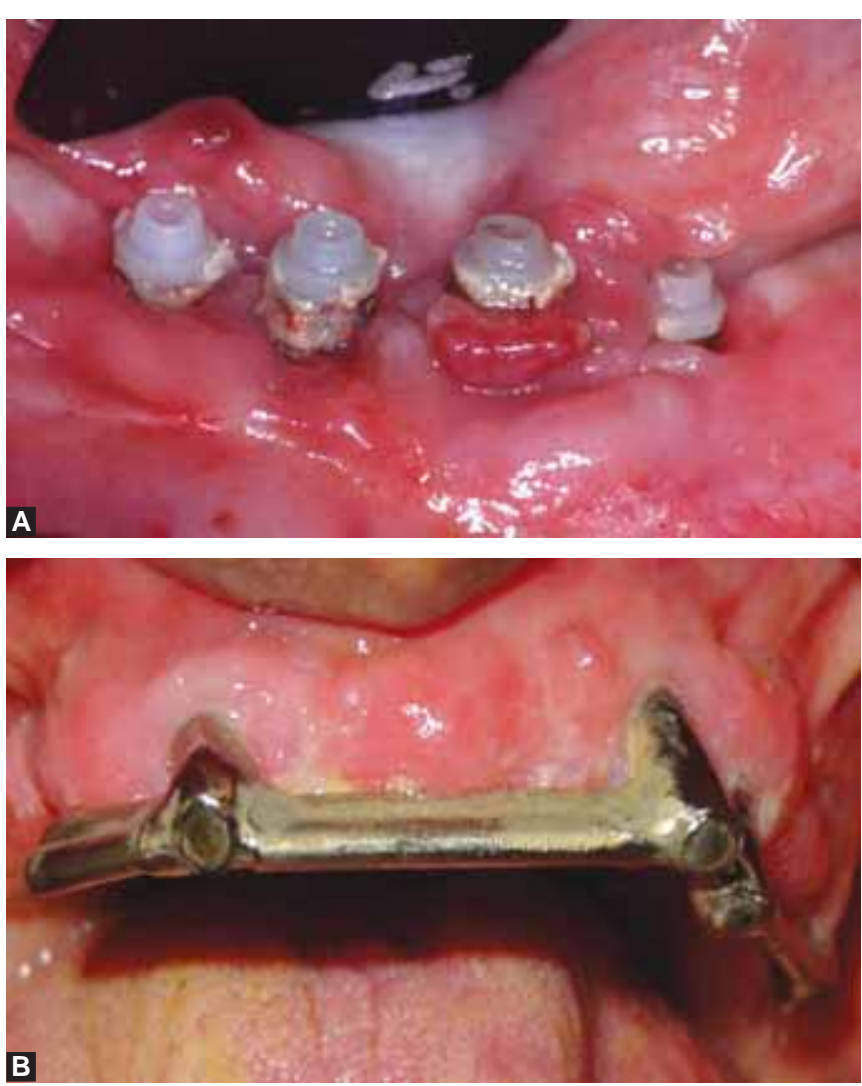

Figs $1 \mathrm{~A}$ and B: Soft-tissue changes are evident in these cases of advanced peri-implantitis at multiple implant sites. Notable are the large amount of local factors (dental plaque and calculus) evident; possibly indicating their etiological significance 
anticipated. ${ }^{2,9}$ Effective evidenced-based diagnostic and therapeutic protocols require an understanding of the nature of peri-implant disease. With rapid progress in research related to peri-implant diseases which includes modern therapeutic modalities such as lasers, there is a continual need to keep abreast of the current evidence. As a first part of the series, this paper aims to present an overview of the current state of knowledge about the case-definition, diagnostic, etiopathology and risk-related aspects of periimplant diseases, while the second part of the series will address aspects of therapeutic interventions, as highlighted by the clinical case reports.

\section{PERI-IMPLANT DISEASE}

\section{Definitions}

Implant complication is the term assigned to describe when an unexpected deviation occurs from the standard treatment outcome, and further treatment is required after delivery of the prosthesis. ${ }^{10}$ Peri-implant diseases occur at a previously stable integrated implant and hence constitute a late biological complication. The term peri-implantitis was introduced by Mombelli et al in $1987^{11}$ describing 'periimplantitis as a site specific infection which yields many features in common with chronic periodontitis'. Since then various definitions have been proposed in literature. ${ }^{12-15}$

Peri-implant diseases are currently defined by the 6th European Workshop on Periodontology in 2008. ${ }^{16}$ The previously adopted definitions at the First European Workshop on Periodontology in $1994^{17}$ described periimplant mucositis as 'a reversible inflammation of the soft tissues surrounding an implant in function with no loss of supporting bone and its clinical signs are bleeding and/or suppuration on probing and increased probing depths (4-5 mm)' and peri-implantitis was defined as 'an inflammatory process affecting the tissues around an osseointegrated implant in function resulting in loss of supporting bone; its' clinical signs were described as deep probing depths ( $>5 \mathrm{~mm}$ ), bleeding and/or suppuration on probing'. In the current definitions proposed by the 6th European Workshop on Periodontology ${ }^{16}$ the terms reversible and irreversible have been removed in an attempt to provide more clinically applicable definitions. Thus, periimplant mucositis is now defined as 'the presence of inflammation of the peri-implant mucosa without signs of loss of bone support' while peri-implantitis is 'characterized by a loss of bone support in addition to inflammation of the mucosa'. In addition, objective diagnostic criteria for periimplant diseases have recently been specified by the 7th European Workshop in Implantology ${ }^{18}$ in 2011 as follows: Peri-implant mucositis: The primary diagnostic criterion is bleeding on gentle probing $(<0.25 \mathrm{~N})$, peri-implantitis: The primary criterion is a change in the crestal bone level in conjunction with bleeding on probing with or without concomitant deepening of peri-implant pockets, while pus is a common finding. These clear definitions and diagnostic standards should be adopted to facilitate comparability among studies reporting implant outcomes.

Moreover, in view of the current evidence, it is also stated that peri-implant diseases are infectious diseases, with reference to microbiological etiology. ${ }^{16,19}$ The role played by occlusal overload in etiology of peri-implantitis had been debated previously and it is now accepted that occlusal overload does not initiate peri-implant tissue inflammation, but exaggerates bone loss in a plaque-induced periimplantitis lesion. ${ }^{20}$

\section{Prevalence}

Reports regarding prevalence of peri-implant diseases show widely varying prevalence rates, which can be explained partially by variable diagnostic criteria adopted by different examiners. A key review ${ }^{19}$ noted that peri-implant mucositis ranges between 24 and 91\%, whereas after a function of 9 to 11 years, patients with peri-implant mucositis ranged between 28 and 56\%. Another systematic review reported peri-implantitis incidence at $8.6 \%$ of implants during 5 years of function. ${ }^{21}$

A tendency for clustering of peri-implant disease among subjects is known, indicating that some individuals are more at risk of developing peri-implant disease (similar to periodontal disease) implying that host susceptibility plays a role in peri-implant inflammation. ${ }^{16,22}$ Another implication of this fact is that studies should be interpreted with regard to both total number of implant failures and also the number of implant failures per individual patient. Another issue is that most studies report short-term data, which may underestimate the long-term burden posed by peri-implant disease. One study that followed implant patients after a function of 9 to 14 years noted that $16 \%$ of patients and $6.6 \%$ all implants presented progressive bone loss $(1.8 \mathrm{~mm}$ or more compared to the 1 year level).$^{15}$ Thus, peri-implant disease is a frequent biological complication when regular supportive therapy is not provided.

\section{Diagnostic Criteria}

Accurate diagnosis of peri-implant disease is essential for appropriate management and requires precise criteria. Comparing clinical and radiographic parameters with baseline data as the reference is the key to diagnosis. ${ }^{18}$ Standard parameters for evaluating peri-implant tissue health may include the following: 
Peri-implant probing: Probing is a reliable procedure for periodontal diagnosis and similarly for the detection of changes in the peri-implant tissue attachment levels. A light probing force $(0.2-0.3 \mathrm{~N})$ is a reliable tool for diagnosing peri-implant health or disease and the probe tip identifies the apical extent of the barrier epithelium in healthy tissues. ${ }^{23,24}$ Similar to natural teeth, the peri-implant epithelial attachment reestablishes after light probing within 4 to 5 days. ${ }^{23}$ However, heavy forces of more than $0.5 \mathrm{~N}$ should not be applied in order to prevent tissue injury. ${ }^{25}$

Bleeding on probing: The presence of bleeding on gentle probing (BOP) indicates mucosal inflammation and is a valuable diagnostic tool. $\mathrm{BOP}$ has been shown to be present at $91 \%$ of peri-implantitis sites. ${ }^{23} \mathrm{BOP}$ is the primary parameter for the diagnosis of peri-implant mucositis. ${ }^{18} \mathrm{BOP}$ also has a high prognostic value, since absence of BOP is strongly indicative of peri-implant tissue stability ${ }^{26}$ and thus essential for monitoring peri-implant health. In fact, the diagnostic accuracy of BOP around implants is significantly higher than that for teeth. ${ }^{18}$ Importantly, light probing forces $(0.25 \mathrm{~N})$ are essential. ${ }^{25}$

Probing depth: Probing depths of healthy peri-implant tissues are noted as slightly higher than around natural teeth. ${ }^{27}$ Different implant systems may differ in permitting access of the probe to the peri-implant sulcus, leading to small differences in probing depths. ${ }^{27}$ Another reason why baseline probing depths can be different for each implant is the difference in positioning of the implant shoulder in relation to the bone crest, with deeper placement being common in esthetic areas. Thus, establishing baseline probing depths for each individual implant is essential so that comparison can be made later. In peri-implantitis, the soft-tissue seal is no longer able to inhibit probe tip penetration past the epithelial attachment. ${ }^{23}$ An increase in probing depth overtime is clinically associated with the loss of implant supporting bone and is a reliable clinical indicator of peri-implant disease. ${ }^{28,29}$ Thus, probing depth (in relation to baseline) should be assessed regularly along with the presence of bleeding on probing and suppuration. Increase in peri-implant probing depth more than $5 \mathrm{~mm}$ along with bleeding on probing (which implies a diagnosis of periimplantitis) indicates a risk for disease progression, similar to periodontitis (Figs 2A and B). ${ }^{18,29}$

Suppuration: The presence of pus is the result of infection and an inflammatory lesion. Its presence has been found to be associated with progressive peri-implant bone loss. ${ }^{29}$

Radiographic assessment: Radiographs are essential to monitor marginal bone levels at implants and diagnose interproximal bone loss. The distance from a fixed reference
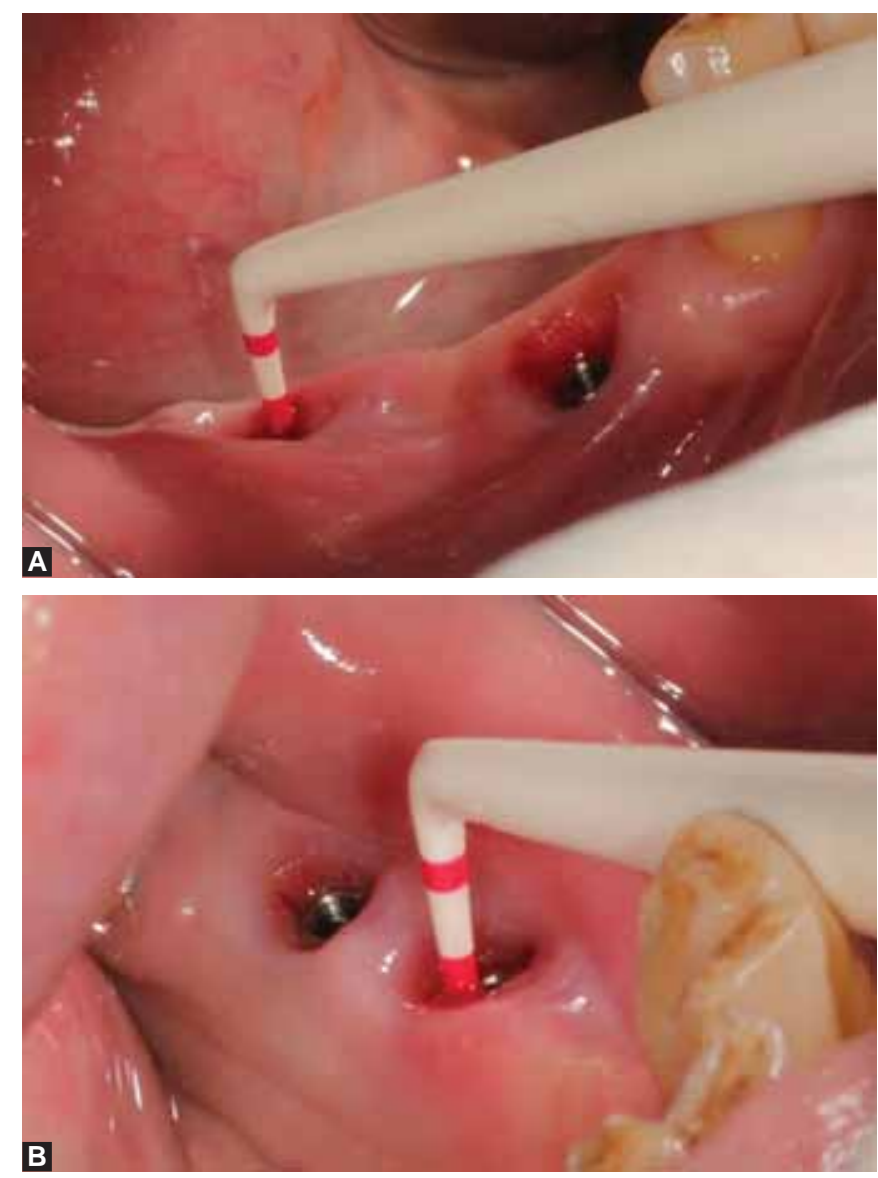

Figs 2A and B: Peri-implant probing (with a color-coded plastic probe) around a symptomatic implant shows a probing depth of more than $5 \mathrm{~mm}$ and bleeding on probing indicating peri-implantitis

point (e.g. implant shoulder or implant-abutment junction) to the interproximal bone level is recorded at baseline and monitored longitudinally. Annual standardized radiographs are advised. ${ }^{16,18}$ However, conventional radiography is limited in its inability to detect early bone changes and so cannot be regarded as a sensitive indicator of early periimplant disease (Figs 3A and B). Moreover, long-term monitoring requires standardizing in order to minimize distortion and facilitate comparison, thus long-cone parallel technique and positioning devices are preferable. ${ }^{20}$ Conventional and cone-beam computed tomography provide accurate three-dimensional representations of periimplant bone defects and overcome the limitations of conventional radiography in estimating bone changes. ${ }^{30} \mathrm{It}$ is imperative to note that radiographic bone-implant contact does not confirm osseointegration at the histological level. ${ }^{31}$ For monitoring patients with multiple implants, panoramic radiography is now advocated due to concerns over radiation levels and agreement for crestal bone height dimensions is proved between panoramic and intraoral radiographs. ${ }^{32}$

Implant mobility: Clinical mobility assessment may be performed similar to that for natural teeth by exertion of force by finger or instrument pressure. ${ }^{33}$ As the peri-implant 

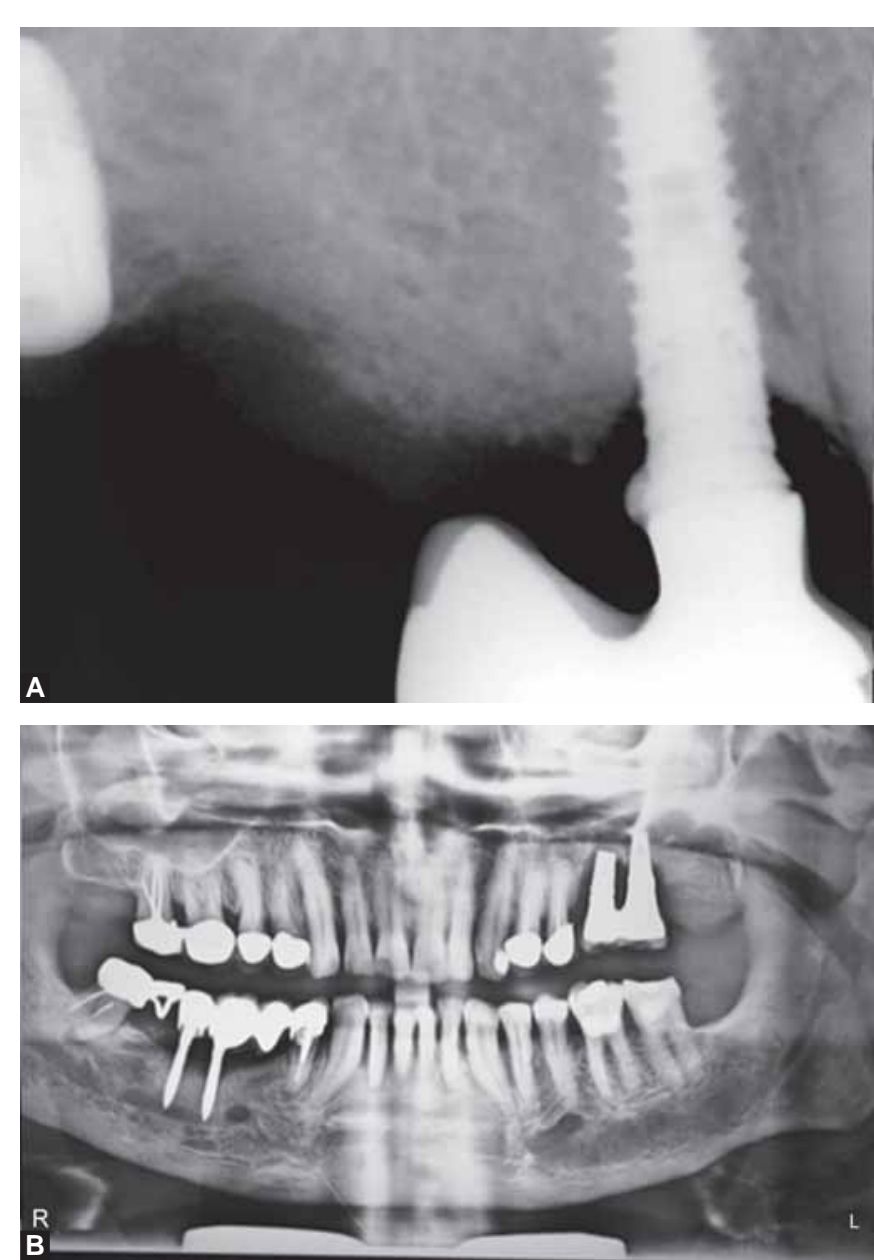

Figs $\mathbf{3 A}$ and B: Radiographic evidence of bone loss in periimplantitis. It is important to realise that radiographs are confirmatory rather than sensitive diagnostic tools, and early changes may not be detectable radiographically

lesion involves progressive loss of marginal bone, ${ }^{3,5-7,10}$ the implant still remains osseointegrated in its apical aspect and this prevents any increase in clinical mobility. The presence of clinically discernible mobility when vertical or horizontal forces (of less than $500 \mathrm{gm}$ ) are applied implies complete loss of osseointegration; ${ }^{34}$ such an implant should be designated as failed and thus removed. Healthy implants, even though clinically immobile, are not truly rigid and possess subclinical levels of mobility similar to natural teeth. ${ }^{35}$ Additional and more sensitive methods to assess subclinical levels of implant mobility include resonance frequency analysis (RFA) (Ostell ${ }^{\circledR}$ Integration Diagnostics, Sävedalen, Sweden) and periotest instruments. While there are limitations regarding the operator variability and sensitivity of periotest values, RFA values are comparatively more precise. ${ }^{36}$ Although there is evidence that serially decreasing RFA or increasing periotest values are indicative of ongoing bone loss, ${ }^{37,38}$ until now there are no accepted critical threshold values of these tests that may be used to predict implant failure or success ${ }^{34,37-39}$ so their routine clinical use for monitoring is not currently advocated.
Although advanced peri-implantitis lesions may be clearly evident, regular longitudinal monitoring is essential to detect early peri-implant disease in order to prevent progression by initiating interceptive therapy. Baseline record of attachment and bone level values should be done at the time of prosthesis connection (except in case of immediately loaded implants) ${ }^{30}$ as initial crestal remodeling is expected before this and any bone loss which is noted subsequently may be attributed to bacterial infection. ${ }^{18}$

\section{Etiopathology of Peri-implant Disease}

Biofilm at peri-implant sites: In terms of etiopathology, periimplant disease is very similar to periodontal disease; both being initiated by a pathogen containing plaque biofilm. At clinically healthy implant sulci, the biofilm comprises predominantly of gram-positive facultative microbiota, similar to that at natural teeth. Bacterial colonization of the peri-implant sulcus begins almost immediately (30 minutes) after a transmucosal (abutment) connection. ${ }^{40}$ The plaque biofilm that develops at implant sites closely resembles that at neighboring teeth. ${ }^{41}$ Therefore, if periodontal pockets persist at sites adjacent to implants there is a risk for colonization of the peri-implant sulcus by periodontal pathogens; this implies the necessity of controlling periodontal disease beforehand. The microbiology of plaque at peri-implant mucositis and peri-implantitis is closely similar to that at gingivitis and periodontitis respectively. Peri-implantitis sites typically yield high proportions of gram-negative anaerobes or red complex periodontal pathogens such as P.gingivalis. ${ }^{42}$ Current evidence indicates some differences as well. Organisms, such as S. aureus and $M$. oralis have been detected more frequently at peri-implant pockets and may have an etiological significance. ${ }^{43,44}$

Host response in peri-implant diseases: The initial tissue response to the biofilm is histologically similar at gingivitis and peri-implant mucositis sites. However, a persistent microbial challenge initiates more extensive inflammatory infiltrate in peri-implant sites as compared to periodontal tissue, resulting in earlier progression to marrow spaces. ${ }^{45}$ Periodontitis sites, unlike peri-implantitis sites have a supracrestal connective tissue fiber attachment on the tooth, which walls off the alveolar bone more effectively. Other structural differences, such as lower vascularity and cell: collagen ratio also may account for differences in the tissue response. ${ }^{46}$ This results in more frequent rapid progression and bone loss at peri-implantitis sites. In an experimental study, only about $20 \%$ peri-implantitis sites were arrested after removing etiological factors and many remaining sites tended to progress rapidly ${ }^{47}$ and spontaneously; this may imply that effectively controlling the progression of periimplantitis may be more difficult when compared to periodontal disease. 


\section{Risk for Peri-implant Diseases}

Potential risk factors for peri-implant diseases have been addressed by many studies, however in the absence of longterm prospective data that validate a cause-effect relation, most of these factors are termed as 'risk indicators'. ${ }^{30}$

Poor oral hygiene: Poor plaque control significantly increases the risk for peri-implant disease by more than 2.5 times as suprastructural plaque initiates peri-implant muscositis. ${ }^{30}$ Apart from installing the implants in a disease free mouth, patients should be motivated to perform an adequate level of plaque control on a regular basis, especially in interproximal areas. An important clinical implication is the avoidance of overcontoured restorations or imprecise margins, especially subginvially, as this will favor a pathologic shift in subgingival plaque. Regular prophylaxis can result in a greater than 11 fold risk reduction for development of peri-implantitis; ${ }^{48}$ validating that patient compliance and motivation are crucial to long-term implant health.

History of periodontitis: Patients with treated periodontal disease have increased susceptibility to peri-implantitis ${ }^{30}$ especially with regard to aggressive periodontitis. ${ }^{49}$ Recently evidence shows that rather than simply a history of periodontitis, it is actually the recurrence of deep pockets which increases the risk for peri-implantitis; ${ }^{50}$ this may highlight the crucial role of adequate periodontal maintenance in such patients.

Cigarette smoking: Significantly higher peri-implant marginal bone loss occurs in smokers when compared to nonsmokers and smokers have approximately 3 times higher risk of peri-implantitis, although with regard to peri-implant muscositis among smokers, such a risk ratio is lower (about 1.3 times). ${ }^{15,30}$

Diabetes: Diabetes with poor glycemic control, an established risk factor for periodontitis, is associated with increased incidence of peri-implant disease. ${ }^{51}$ Interestingly, some recent studies have noted delayed implant integration but no significant increase in implant failure rates among diabetics, ${ }^{52}$ but it is noteworthy that the follow-up periods are short and long-term data might be more conclusive. ${ }^{30}$

Genetic traits: Interleukins play a major role in inflammation. Interleukin 1(IL-1) composite genotype that is linked with periodontitis has also been associated with peri-implantitis and seems to act synergistically with smoking. ${ }^{53}$ This association is yet debated as not all studies support this and therefore routine genetic testing is not recommended for implant patients at this point. ${ }^{30}$

\section{Implant-Related Factors}

Implant surface: Although plaque is the primary factor in initiation of peri-implant disease, implant design and surface characteristics may contribute to variability in risk for disease progression. The Sa value is an amplitude parameter of the implant surface (mean height deviation of a surface area). ${ }^{54}$ Implant surfaces are commonly classified into four categories depending on surface roughness (Sa) values as; smooth, minimally rough, moderately rough or rough. ${ }^{54,55}$ Most currently marketed implants have moderately rough surfaces (Sa between 1.0 and $2.0 \mu \mathrm{m}$ ), which is optimal for bone healing response. ${ }^{54}$ The surface of the implant may impact the biofilm retention ${ }^{56}$ and implants with very rough surfaces (Sa more than 2), such as the titanium plasma sprayed (TPS) surface and hydroxyapatite (HA) coated surface increase odds of peri-implantitis. ${ }^{30,57}$ However, as data regarding implant surface influences on peri-implant disease ${ }^{58}$ is limited and the current consensus is that there is insufficient evidence if any particular surface affects periimplant disease pathogenesis differently. ${ }^{18,46}$

Implant placement-related factors: Failure to remove excess cement from the sulcus can contribute to peri-implant infections. Excessively deep implant placement may be a factor resulting in excess cement retention in the sulcus after prosthesis cementation. ${ }^{59}$

\section{Soft-tissue Related Factors}

Width of keratinized peri-implant mucosa: The necessity of having a band of keratinized peri-implant mucosa has been much debated and a consensus is that such evidence is inadequate. ${ }^{49}$ Although implant survival is not noted as significantly different between nonkeratinized and keratinized peri-implant mucosa, ${ }^{60}$ it is noteworthy that some studies do record more peri-implant mucositis and bone loss at implants in nonkeratinized mucosa when a high level of plaque control is absent. ${ }^{61}$ The clinical inference is that operators should prefer techniques that preserve keratinized tissue at implant sites.

Occlusal factors: Experimental animal data documents marginal bone loss at implant sites with uninflammed periimplant mucosa caused by excessive occlusal forces above a bone strain threshold. ${ }^{62}$ Clinically, more bone loss has been observed at sites with increased occlusal forces, such as long tooth-implant supported cantilever. ${ }^{63}$ The current view is that in absence of a biofilm occlusal overload may actually increase bone density by functional stress shielding but in the presence of a plaque-induced inflamed peri-implantitis lesion increased occlusal forces cause more rapid bone loss. ${ }^{20}$ As there is a lack of conclusive evidence of causation, the role occlusal force as a risk factor in development and progress of peri-implant disease is yet unclear.

\section{Other Factors}

Peri-implant diseases are multifactorial in nature and various other potential risk factors are still being addressed. Among 
these, while preliminary studies prove no relation with osteoporosis and bisphosphonate therapy, ${ }^{64,65}$ they indicate the need for better powered studies. Latest studies point to an interplaying role of local bone microstructure with cellular level inflammatory reactions. ${ }^{66}$

\section{CONCLUSION}

Peri-implant diseases are infectious in etiology and similar to periodontal diseases in being initiated by dental plaque. There appears to be a high prevalence with a cumulative increase with time in function. Smoking, poor oral hygiene and concomitant periodontal disease constitute the most significant risk factors. Risk assessment and regular monitoring of peri-implant tissue in comparison to baseline parameters and appropriate supportive care are crucial to preserve clinical health around implants. Once diagnosed, peri-implantitis sites must be assessed for possible therapy without delay to avoid the risk of rapid bone loss. Considering the fact that predictable reosseointegration is yet a challenge, ${ }^{67}$ good supragingival plaque control, cleansable restorations, a strict supportive therapy regime are of absolute importance for preventing peri-implant disease.

\section{REFERENCES}

1. Branemark PI, Zarb GA, Albrektsson T. Tissue-integrated prosthesis: Osseointegration in clinical dentistry. Chicago: Quintessence Publishing Co. Inc 1985.

2. Walton TR. Changes in patient and FDP profiles following the introduction of osseointegrated implant dentistry in a prosthodontic practice. Int J Prosthodont 2009;22:127-35.

3. Esposito M, Hirsch JM, Lekholm U, Thomsen P. Biological factors contributing to failures of osseointegrated implants (I). Success criteria and epidemiology. Eur J Oral Sci 1998;106: e527-51.

4. Albrektsson T, Dahl E, Enbom L, Engevall S, Engquist B, Eriksson AR, et al. Osseointegrated oral implants. A Swedish multicenter study of 8139 consecutively inserted nobelpharma implants. J Periodontol 1988;59:287-96.

5. Pontoriero R, Tonelli MP, Carnevale G, Mombelli A, Nyman SR, Lang NP. Experimentally induced peri-implant mucositis. A clinical study in humans. Clin Oral Impl Res1994;5:254-59.

6. Mombelli A, Lang NP. The diagnosis and treatment of periimplantitis. Periodontology 2000. 1998;17:63-76.

7. Lang NP, Wilson TG, Corbet EF. Biological complications with dental implants: Their prevention, diagnosis and treatment. Clin Oral Impl Res 2000;11(Suppl. 1):146-55.

8. Albrektsson T, Zarb GA, Worthington P, Eriksson AR. The longterm efficacy of currently used dental implants: A review and proposed criteria of success. Int J Oral Maxillofac Implants 1986;1:e11-25.

9. Grusovin MG, Worthington HV. Interventions for replacing missing teeth: Treatment of peri-implantitis. Esposito M, Cochrane Database Syst Rev18 Jan 2012;1:CD004970.

10. Lang NP, Berglundh T, Heitz-Mayfield LJ, Pjetursson BE, Salvi GE, Sanz M. Consensus statements and recommended clinical procedures regarding implant survival and complications. Int J Oral Maxillofac Implants 2004;19(Suppl):150-54.
11. Mombelli A, van Oosten MA, Schurch E Jr, Lang NP. The microbiota associated with successful or failing osseointegrated titanium implants. Oral Microbiol Immunol 1987;2:145-51.

12. Tonetti MS, Schmid J. Pathogenesis of implant failures. Periodontol 2000. 1994;4:127-38.

13. Esposito $\mathrm{M}$, Thomsen $\mathrm{P}$, Ericson LE, Lekholm U. Histopathologic observations on early oral implant failures. Int J Oral Maxillofac Implants 1999;14:798-810.

14. Laney WR. In. Glossary of Oral and Maxillofacial Implants. Berlin. Quintessence Publishing 2007;123.

15. Roos-Jansaker AM, Lindahl C, Renvert H, Renvert S. Nine- to fourteen-year follow-up of implant treatment. Part II: Presence of peri-implant lesions. J Clin Periodontol 2006;33:290-95.

16. Lindhe J, Meyle J. Peri-implant diseases: Consensus report of the sixth European workshop on periodontology. J Clinical Periodontol. 2008;35(Suppl. 8):282-85.

17. Albrektsson T, Isidor F. Consensus report of session IV. In: Lang N, Karring T (Eds). Proceedings of the 1st European workshop on periodontology. Switzerland: Quintessence, 1994:365.

18. Lang NP, Berglundh T. Peri-implant diseases: Where are we now? - Consensus of the seventh European workshop on periodontology. J Clin Periodontol 2011;38:178-81.

19. Zitzmann NU, Berglundh T. Definition and prevalence of periimplant diseases. J Clin Periodontol 2008;35:286-91.

20. Chambrone L, Chambrone LA, Lima LA. Effects of occlusal overload on peri-implant tissue health: A systematic review of animal-model studies. J Periodontol 2010;81:1367-78.

21. Pjetursson BE, Tan K, Lang NP, Brägger U, Egger M, Zwahlen M. A systematic review of the survival and complication rates of fixed partial dentures (FPDs) after an observation period of at least 5 years. Clin Oral Implants Res 2004;15:625-42.

22. Schwartz-Arad D, Laviv A, Levin L. Failure causes, timing, and cluster behavior: An 8-year study of dental implants. Implant Dent 2008;17:200-07.

23. Lang NP, Wetzel AC, Stich H, Caffesse RG. Histologic probe penetration in healthy and inflamed peri-implant tissues. Clin Oral Implants Res 1994;5:191-201.

24. Abrahamsson I, Soldini C. Probe penetration in periodontal and peri-implant tissues. An experimental study in the beagle dog. Clin Oral Implants Res 2006;17:601-05.

25. Mombelli A, Muumlhle T, Brägger U, Lang NP, Bürgin WB. Comparison of periodontal and peri-implant probing by depthforce pattern analysis. Clin Oral Impl Res 1997;8:448-54.

26. Luterbacher S, Mayfield L, Brägger U, Lang NP. Diagnostic characteristics of clinical and microbiological tests for monitoring periodontal and peri-implant mucosal tissue conditions during supportive periodontal therapy (SPT). Clin Oral Implants Res 2000;11:521-29.

27. Christensen MM, Joss A, Lang NP. Reproducibility of automated periodontal probing around teeth and osseointegrated oral implants. Clin Oral Implants Res 1997;8:455-64.

28. Quirynen M, van Steenberghe D, Jacobs R, Schotte A, Darius P. The reliability of pocket probing around screw-type implants. Clin Oral Implants Res 1991;2:186-92.

29. Fransson C, Wennström J, Berglundh T. Clinical characteristics at implants with a history of progressive bone loss. Clin Oral Impl Res 2008;19:142-47.

30. Heitz-Mayfield LJ. Peri-implant diseases: Diagnosis and risk indicators. J Clin Periodontol 2008;35:292-304.

31. Sewerin IP, Gotfredsen K, Stoltze K. Accuracy of radiographic diagnosis of peri-implant radiolucencies-An in vitro experiment. Clin Oral Implants Res 1997;8:299-304. 
32. Persson RE, Tzannetou S, Feloutzis AG, Brägger U, Persson GR, Lang NP. Comparison between panoramic and intraoral radiographs for the assessment of alveolar bone levels in a periodontal maintenance population. J Clin Periodontol 2003; 30:833-39.

33. Nedir R, Bischof M, Szmukler-Moncler S, Bernard JP, Samson J. Predicting osseointegration by means of implant primary stability. Clin Oral Implants Res 2004;15:520-28.

34. Misch CE, Perel ML, Wang HL, Sammartino G, GalindoMoreno P, Trisi P, et al. Implant success, survival and failure: The international congress of oral implantologists (ICOI). Pisa consensus conference.Implant Dent 2008;17:5-15.

35. Boldt J, Knapp W, Proff P, Rottner K, Richter EJ. Measurement of tooth and implant mobility under physiological loading conditions. Ann Anat 14 Oct 2011.

36. Zix J, Hug S, Kessler-Liechti G, Mericske-Stern R. Measurement of dental implant stability by resonance frequency analysis and damping capacity assessment: Comparison of both techniques in a clinical trial. Int J Oral Maxillofac Implants 2008;23: 525-30.

37. Sennerby L, Meredith N. Implant stability measurements using resonance frequency analysis: Biological and biomechanical aspects and clinical implications. Periodontol 2000. 2008;47: 51-66.

38. Aparicio C, Lang NP, Rangert B. Validity and clinical significance of biomechanical testing of implant/bone interface. Clin Oral Implants Res 2006;17(Suppl 2):2-7.

39. Sennerby L, Persson LG, Berglundh T, Wennerberg A, Lindhe J. Implant stability during initiation and resolution of experimental peri-implantitis: An experimental study in the dog. Clin Implant Dent Relat Res 2005;7:136-40.

40. Furst MM, Salvi GE, Lang NP, Persson GR. Bacterial colonization immediately after installation on oral titanium implants. Clin Oral Implants Res 2007:18:501-08.

41. De Boever AL, De Boever JA. Early colonization of nonsubmerged dental implants in patients with a history of advanced aggressive periodontitis. Clin Oral Implants Res 2006: 17:8-17.

42. Hultin M, Gustafsson A, Hallström H, Johansson LA, Ekfeldt A, Klinge B. Microbiological findings and host response in patients with peri-implantitis. Clin Oral Implants Res 2002; 13:349-58.

43. Pye AD, Lockhart DE, Dawson MP, Murray CA, Smith AJ. A review of dental implants and infection. J Hosp Infect 2009; 72:104-10.

44. Faveri M, Gonçalves LF, Feres M, Figueiredo LC, Gouveia LA, et al. Prevalence and microbiological diversity of Archaea in peri-implantitis subjects by $16 \mathrm{~S}$ ribosomal RNA clonal analysis. J Periodontal Res 2011;46:338-44.

45. Lindhe J, Berglundh T, Ericsson I, Liljenberg B, Marinello C. Experimental breakdown of peri-implant and periodontal tissues. A study in the beagle dog. Clin Oral Implants Res 1992;3:9-16.

46. Heitz-Mayfield LJA, Lang NP. Comparative biology of chronic and aggressive periodontitis vs peri-implantitis. Periodontology 2000. 2010;53:167-81.

47. Zitzmann NU, Berglundh T, Ericsson I, Lindhe J. Spontaneous progression of experimentally induced peri-implantitis. J Clin Periodontol 2004;31:845-49.

48. Rinke S, Ohl S, Ziebolz D, Lange K, Eickholz P. Rinke S, et al. Prevalence of peri-implant disease in partially edentulous patients: A practice-based cross-sectional study. Clin Oral Implants Res 2011;22:826-33.
49. Renvert S, Persson GR. Periodontitis as a potential risk factor for peri-implantitis. J Clin Periodontol 2009;36:10:9-14.

50. Cho-Yan Lee J, Mattheos N, Nixon KC, Ivanovski S. Residual periodontal pockets are a risk indicator for peri-implantitis in patients treated for periodontitis. Clin Oral Implants Res 2012; 23:323-33

51. Ferreira SD, Silva GL, Cortelli JR, Costa JE, Costa FO. Prevalence and risk variables for peri-implant disease in Brazilian subjects. J Clin Periodontol 2006;33:929-35.

52. Turkyilmaz I. One-year clinical outcome of dental implants placed in patients with type 2 diabetes mellitus: A case series. Implant Dent 2010;19:323-29.

53. Laine ML, Leonhardt A, Roos-Jansåker AM, Peña AS, van Winkelhoff AJ, Winkel EG, Renvert S. IL-1RN gene polymorphism is associated with peri-implantitis. Clin Oral Implants Res 2006;17:380-85.

54. Albrektsson T, Wennerberg A. Oral implant surfaces: Part 1review focusing on topographic and chemical properties of different surfaces and in vivo responses to them. Int J Prosthodont 2004;17:536-43.

55. Wennerberg A, Albrektsson T. On implant surfaces: A review of current knowledge and opinions. Oral Maxillofac Implants 2010;25:63-74.

56. Teughels W, Van Assche N, Sliepen I, Quirynen M. Effect of material characteristics and/or surface topography on biofilm development. Clin Oral Implants Res 2006;17(Suppl 2):68-81.

57. Karoussis IK, Bragger U, Salvi GE, Burgin W, Lang NP. Effect of implant design on survival and success rates of titanium oral implants: A 10-year prospective cohort study of the ITI Dental Implant System. Clin Oral Implants Res 2004;15:8-17.

58. Renvert S, Polyzois I, Claffey N. How do implant surface characteristics influence peri-implant disease? J Clin Periodontol 2011;38(Suppl 11):214-22.

59. Lang NP, Tonetti M. Peri-implantitis: Etiology, pathogenesis, prevention and therapy, In: Dental implant complications etiology, prevention, and treatment: Forum SJ (Ed). Blackwell Publishing, West Sussex, United Kingdom 2010.

60. Esposito M, Grusovin MG, Maghaireh H, Coulthard P, Worthington HV. Interventions for replacing missing teeth: Management of soft-tissues for dental implants. Cochrane Database Syst Rev 2007;18.

61. Bouri A Jr, Bissada N, Al-Zahrani MS, Faddoul F, Nouneh I. Width of keratinized gingiva and the health status of the supporting tissues around dental implants. Int J Oral Maxillofac Implants 2008;23:323-26.

62. Miyata T, Kobayashi Y, Araki H, Ohto T, Shin K. The influence of controlled occlusal overload on peri-implant tissue. Part 3: A histologic study in monkeys. Int J Oral Maxillofac Implants 2000;15:425-31.

63. Baron M, Haas R, Baron W, Mailath-Pokorny G. Peri-implant bone loss as a function of tooth-implant distance. Int $\mathrm{J}$ Prosthodont 2005;18:427-33.

64. Dvorak G, Arnhart C, Heuberer S, Huber CD, Watzek G, Gruber R. Peri-implantitis and late implant failures in postmenopausal women: A cross-sectional study. J Clin Periodontol 2011;38: 950-55.

65. Shabestari GO, Shayesteh YS, Khojasteh A, Alikhasi M, Moslemi N, Aminian A, et al. Implant placement in patients with oral bisphosphonate therapy: A case series. Clin Implant Dent Relat Res 2010; 12:175-80.

66. Serino G, Turri A. Extent and location of bone loss at dental implants in patients with peri-implantitis. J Biomech 2011; 11:267-71. 
67. Renvert S, Polyzois I, Maguire R. Reosseointegration on previously contaminated surfaces: A systematic review. Clin Oral Implants Res Sep 2009;20(Suppl 4):216-27.

\section{ABOUT THE AUTHORS}

\section{Rohit Karnik}

Diplomate in Laser Dentistry (Indian Academy of Laser Dentistry) Reader, Department of Periodontics, Yogita Dental College and Hospital, Khed, Maharashtra, India

\section{Suchetan Pradhan}

Founder President, Indian Academy of Laser Dentistry, Director Department of Laser Dentistry, Manipal, Professor, Department of Implantology, SS Dental College, Hyderabad, Andhra Pradesh, India

\section{CORRESPONDING AUTHOR}

Suchetan Pradhan, Gunjarav, Gulmohar Cross Road No. 7, Juhu Mumbai, Maharashtra-400049, India, Phone: 0222624 4324, e-mail: suchetanpradhan@gmail.com 